\title{
An Economical and Facile Route to Produce Gram-Scale and Phase-Selective Copper Sulfides for Thermoelectric Applications
}

\author{
Rafiq Mulla $^{1}$, Daniel R. Jones ${ }^{1}$, and Charles W. Dunnill ${ }^{1 *}$ \\ ${ }^{1}$ Energy Safety Research Institute, Swansea University, Bay Campus, Fabian Way, SA1 8EN, UK. \\ *E-mail address: c.dunnill@swansea.ac.uk
}

\begin{abstract}
:
Producing thermoelectric materials without energy-intensive processes is essential to reduce production costs and for wide-scale applications. Copper sulfides have recently been identified as new and promising environmentally friendly thermoelectric materials. Here, an economical synthetic route for the gram-scale preparation of copper sulfide is developed that enables selective control of the copper oxidation state, in turn allowing the stoichiometry be tuned in order to optimise the thermoelectric characteristics of the product. Through this facile and scalable protocol, $\mathrm{CuS}, \mathrm{Cu}_{1.75} \mathrm{~S}, \mathrm{Cu}_{1.80} \mathrm{~S}$, and $\mathrm{Cu}_{2} \mathrm{~S}$ powders have been synthesised in conjunction with X-ray diffraction, X-ray photoelectron spectroscopy and Energydispersive X-ray spectroscopy to verify the stoichiometry of each material. The as-prepared compounds were further characterised by thermoelectric measurements and the performance of a test generator module containing ten p-type $\mathrm{Cu}_{2} \mathrm{~S}$ legs was subsequently investigated. Upon heating one side of the module to $70{ }^{\circ} \mathrm{C}$, the device produced an output voltage of 30.9 $\mathrm{mV}$ and a corresponding power output of $3.4 \mu \mathrm{W}$, which is comparable to the power outputs of many of devices fabricated with expensive and toxic thermoelectric elements. This work presents a novel pathway for the development of low-cost thermoelectric devices by introducing a facile, tunable and high-yield $\mathrm{Cu}_{\mathrm{x}} \mathrm{S}$ synthesis procedure that may be readily adapted to other metal sulfides.
\end{abstract}

KEYWORDS: Thermoelectric; copper sulfide; economical synthesis; thermoelectric generator; large-scale production. 


\section{INTRODUCTION}

Metal sulfides have gained much interest as a new class of materials due to their unique electrical properties, ${ }^{1-3}$ with uses in a wide range of potential applications including solar cells, ${ }^{4}$ light-emitting diodes (LEDs), ${ }^{5}$ sensors, ${ }^{6}$ energy storage, ${ }^{7-9}$ thermoelectrics, ${ }^{10-13}$ biomedical labelling, ${ }^{14}$ plasmonics, ${ }^{15,}{ }^{16}$ and catalysis. ${ }^{17-19}$ In recent years, there is a growing interest in utilizing the industrial and automobile waste heat using thermoelectric technology and hence thermoelectric generators are becoming important due to their ability to directly convert the heat gradient into electric potential; the generated potential can also be utilized to produce hydrogen using water splitting units. ${ }^{20-25}$ In such applications, the abundant availability of the raw materials is a prerequisite as the devices like thermoelectric generators/modules require a large amount of thermoelectric powders to fabricate p-type and n-type legs. ${ }^{26-28}$ Many of the best and commercially successful materials are becoming increasingly scarce and expensive. ${ }^{29,30}$ Therefore, alternative abundant materials with better properties are in urgent demand. ${ }^{29,31-33}$ Recently, copper sulfide-based compounds have been in focus since the compounds like $\mathrm{Cu}_{1.8} \mathrm{~S}$ and $\mathrm{Cu}_{1.97-2.00} \mathrm{~S}$ were revealed to be promising as compared to other expensive and commonly used materials. ${ }^{34,}{ }^{35}$ Also, improvements in the thermoelectric properties of copper sulfides have been observed by fabricating composites of copper sulfides or by incorporating impurities into the copper sulfide matrix..$^{36-38}$

In contrast to many other thermoelectric materials, copper sulfides offer long-term sustainability due to the high terrestrial abundance of copper and sulfur. ${ }^{10,39,40}$ Due to this availability and the low cost, low toxicity and desirable electronic and thermal properties of the material, copper sulfide has emerged as a primary candidate for thermoelectric applications. ${ }^{12,} 39$ Many fabrication methods have been reported for the bulk synthesis of copper sulfide powders, including melt solidification, ${ }^{35}$ spark plasma sintering (SPS), ${ }^{41}$ long time mechanical alloying followed by SPS, ${ }^{42,43}$ and hydrothermal techniques. ${ }^{44,}{ }^{45}$ However, 
all of these processes are either prohibitively time-consuming or characteristically energyintensive due to requisite conditions such as elevated temperature, inert atmosphere, and high pressure. Although the solution-phase synthesis of large-scale copper sulfides can conversely be achieved at near-ambient conditions, these procedures typically require the use of numerous reagents to control or change the oxidation states of the ions or to moderate the rate of reaction. ${ }^{46}$ In general, such reactions produce noticeable waste by-products and also exhibit lower yields than the solid-state methods. Here, a low-temperature solution-based protocol has been developed that overcomes the problems of existing synthesis procedures, enabling the selective, gram-scale synthesis of $\mathrm{Cu}_{\mathrm{x}} \mathrm{S}$ powders with controllable stoichiometry. Due to the remarkable simplicity of the presented method, there is considerable scope for further scale-up as a route towards commercial production of $\mathrm{Cu}_{\mathrm{x}} \mathrm{S}$ compounds, in turn reducing the production cost of these materials and thereby facilitating the economical fabrication of $\mathrm{Cu}_{\mathrm{x}} \mathrm{S}$-based thermoelectric generators.

\section{EXPERIMENTAL DETAILS}

\section{Synthesis Procedure}

Copper sulfide samples were prepared by directly mixing elemental $\mathrm{Cu}(99.9 \%$, Alfa Aesar) and S (99.5\%, Alfa Aesar) powders in hydrazine hydrate/water solvent under open-air conditions. Caution: hydrazine hydrate is highly toxic and should be handled with appropriate protecting equipment to prevent contact. A general representation of the synthesis protocol of the $\mathrm{Cu}_{\mathrm{x}} \mathrm{S}$ powders is schematically shown in Figure 1. In a typical synthesis, $\mathrm{Cu}$ and $\mathrm{S}$ powders were added in stoichiometric quantities to a glass vial (20 $\mathrm{ml}$ capacity) up to a combined mass of $c a .5 \mathrm{~g}$, followed by the dropwise addition of hydrazine hydrate $(5 \mathrm{ml})$ under continuous magnetic stirring. The stirring orange-brown suspension was heated slowly to $80{ }^{\circ} \mathrm{C}$, yielding dark brown/black particles after approximately five minutes and the subsequent formation of thick slurry after a further 30 minutes; as shown in Figure 2, 
photographs were recorded at 5 minutes intervals in order to visually track the progress of the reaction mixture during this 30 minute period.

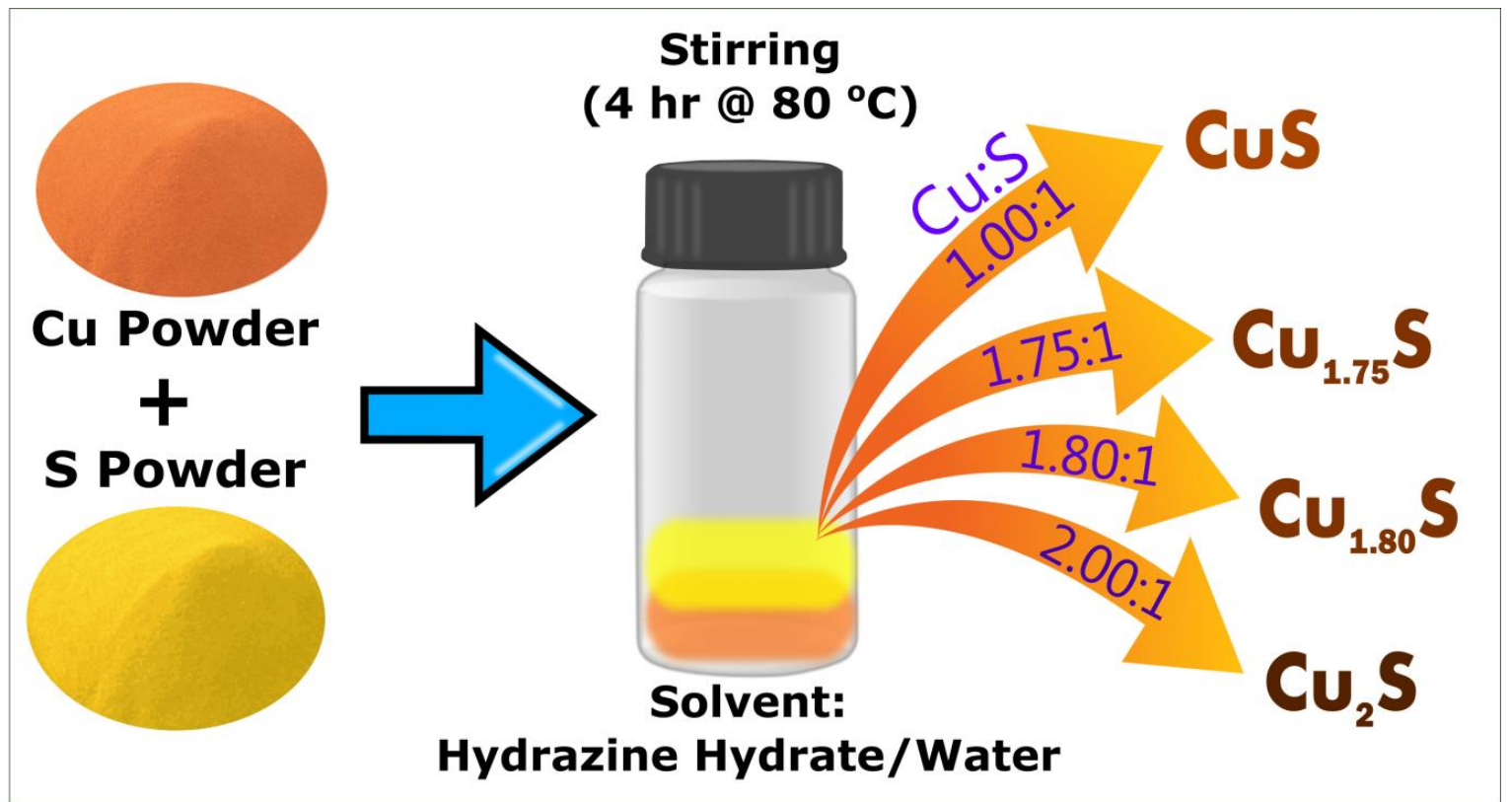

Figure 1. Schematic representation of the synthesis protocol for the preparation of bulk copper sulfide of desired stoichiometry obtained from $\mathrm{Cu}$ and $\mathrm{S}$ powders with respective starting $\mathrm{Cu}: \mathrm{S}$ atomic ratio.

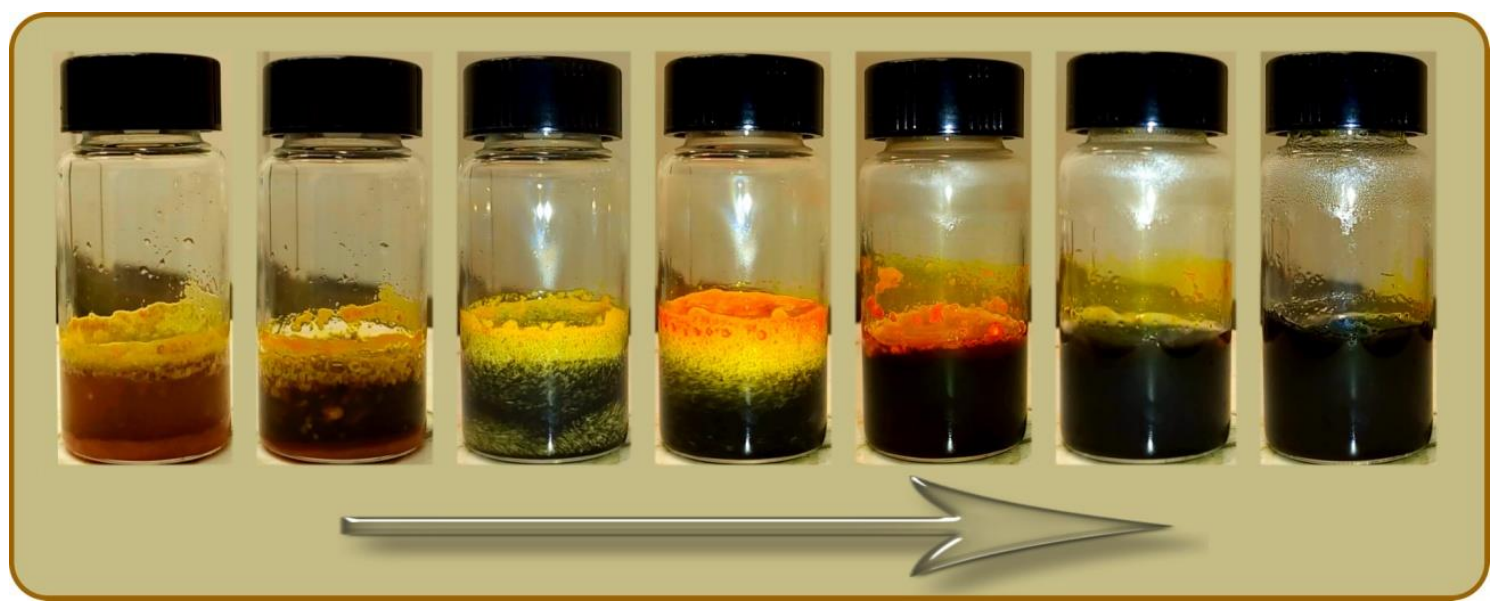

Figure 2. Photographs captured at 5 minutes intervals of the initial reaction during the synthesis to show the conversion of $\mathrm{Cu}$ and $\mathrm{S}$ powders into copper sulfide.

In preparation for more prolonged reaction of the $\mathrm{Cu}$ and $\mathrm{S}$ precursors, de-ionized water $(5 \mathrm{ml})$ was next added to the reaction mixture to decrease the viscosity of the slurry and thereby facilitate rotation of the magnetic stir-bar. The mixture was stirred for a period of 4 
hours at a constant temperature of $80{ }^{\circ} \mathrm{C}$ before cooling naturally to room temperature, whereupon the resulting slurry was dispersed in copious de-ionized water and sonicated for $20 \mathrm{~min}$. The solid $\mathrm{Cu}_{\mathrm{x}} \mathrm{S}$ products were collected by centrifugation and dried in an oven at 60 ${ }^{\circ} \mathrm{C}$ under open-air conditions.

A simple thermoelectric generator was fabricated on a microscope glass slide (size: 25 $\mathrm{mm} \times 75 \mathrm{~mm}$ ) by connecting ten copper sulfide pellets (diameter $5 \mathrm{~mm}$, thickness $\sim 3.5 \mathrm{~mm}$ ) in series with the help of $\mathrm{Cu}$ tape. It is a simple copper sulfide (p-type) based generator and has no corresponding n-type legs. The electrical connection between the pellets and $\mathrm{Cu}$ tape was established using silver paste.

\section{Material Characterization}

Powder X-ray diffraction (XRD) patterns of the $\mathrm{Cu}_{\mathrm{x}} \mathrm{S}$ products were acquired through use of a Bruker D8 diffractometer with $\mathrm{Cu} \mathrm{K} \alpha$ radiation, applying a $2 \theta$ step-size of $0.025^{\circ}$ and $0.5 \mathrm{~s}$ dwell time. Scanning electron microscopy (SEM) was employed to examine the morphology of each powder, using a Hitachi S4800 FE-SEM system with an accelerating voltage of 10 $\mathrm{kV}$ and an emission current of $10 \mu \mathrm{A}$. EDX measurements were recorded by an Oxford Instruments energy-dispersive X-ray (EDX) detector attached to Zeiss Evo LS25 SEM system with $50 \mathrm{~mm}^{2}$ active area, for which an accelerating voltage of $20 \mathrm{kV}$ and emission current $20 \mu \mathrm{A}$ were utilised. To complement these measurements of bulk chemical composition, the surface chemistry of each material was investigated through X-ray photoelectron spectroscopy performed using a Kratos Axis Supra instrument with Al Ka radiation. Sample pellets of $5 \mathrm{~mm}$ diameter were prepared using a 2 tonne press with a pressing time of 20 minutes, and XPS scans were recorded over a rectangular area of 700 $\mu \mathrm{m} \times 300 \mu \mathrm{m}$ on the pellet surface, with the X-ray power and emission current set to $225 \mathrm{~W}$ and $15 \mathrm{~mA}$, respectively. XPS survey scan measurements were performed over energy range of $0-1200 \mathrm{eV}$ at a step size $1 \mathrm{eV}$, dwell time $100 \mathrm{~ms}$ and pass energy $160 \mathrm{eV}$. Core level XPS 
spectra were obtained with pass energy $20 \mathrm{eV}$, dwell time $1000 \mathrm{~ms}$, and at a step size 50 meV. A charge neutralizer working at $3.3 \mathrm{~V}$ with filament bias of $1.0 \mathrm{~V}$ and current of $0.4 \mathrm{~A}$ was used for the charge compensation. All the XPS spectra were "carbon-corrected" by referencing the binding energy of the $\mathrm{C} 1 \mathrm{~s}$ peak to a characteristic value of $284.8 \mathrm{eV}$ for adventitious organic compounds. The data were processed in CasaXPS software and the core level spectra were fitted with Gaussian-Lorentzian components above a Shirley-type background.

For each $\mathrm{Cu}_{\mathrm{x}} \mathrm{S}$ compound, the Seebeck voltage $(\Delta V)$ across a sample pellet of $5 \mathrm{~mm}$ diameter (thickness 3.5-6.0 $\mathrm{mm}$ ), prepared as before, was measured as a function of the temperature gradient $(\Delta T)$ between the top and bottom faces; these tests were conducted using a lab-built apparatus. From these measurements, the Seebeck coefficient $(S)$ was estimated at different temperatures using the standard expression, ${ }^{47}$

$$
S=-\left(\frac{\Delta V}{\Delta T}\right)
$$

where the voltage contribution of the electrodes were subtracted from the observed Seebeck coefficient by referring standard procedure. ${ }^{48,} 49$ About $3-5{ }^{\circ} \mathrm{C}$ temperature gradients were applied across the pellets and the average of hot side and cold side temperature was considered as measurement temperature. Minor shifts of about $1-2{ }^{\circ} \mathrm{C}$ has been applied to these average temperatures whenever necessary to make data points of equal gaps, for ex. the actual average temperature $24{ }^{\circ} \mathrm{C}$ was treated as $25^{\circ} \mathrm{C}$ or $31{ }^{\circ} \mathrm{C}$ as $30^{\circ} \mathrm{C}$, and so on. This adjustment was necessary to estimate other parameters such as power factor $(P F)$ of the samples at different temperatures; it was calculated from the Seebeck coefficient and electrical conductivity values of respective temperatures using a standard equation, $P F=S^{2} \sigma$, where $\sigma$ is the electrical conductivity.

The resistivity $(\rho)$ of the pellets was estimated at temperatures $(T)$ between room temperature and $100{ }^{\circ} \mathrm{C}$ using a four-probe technique: by applying a current $(I)$ across the 
pellet and measuring the potential difference $(V)$ across a second pair of contacts on the sample wall, it was possible to evaluate $\rho$ through the equation ${ }^{50}$

$$
\rho=\frac{V}{I}\left(\frac{A}{d}\right)
$$

where $d$ denotes the distance between the potential probes and $A$ is the cross-sectional area of the sample. Then the inverse values of $\rho$ have then estimated to obtain electrical conductivity $(\sigma)$. For these measurements, the measuring apparatus was placed inside a closed oven and the temperature was recorded through use of a K-type thermocouple. Furthermore, all measurements involved in the estimation of $S$ and $\sigma$ were averaged over three repeat experiments at each value of $T$, thereby enabling estimation of the experimental uncertainties in these quantities. All the pellets used for the measurements were having relative density of 93-96\%. The characteristics of the as-fabricated device was made by heating the underside of the device to $40^{\circ} \mathrm{C}, 50{ }^{\circ} \mathrm{C}, 60^{\circ} \mathrm{C}$, and $70^{\circ} \mathrm{C}$ and measuring resulting open-circuit voltage $\left(V_{o}\right)$ and short circuit current $\left(I_{o}\right)$; the power output at each heating temperature was estimated using standard equation, ${ }^{51}$

$$
P=\frac{V_{O} I_{O}}{4}
$$

\section{RESULTS \& DISCUSSION}

\section{Structural and Chemical Characterizations}

As illustrated schematically in Figure 2, various compositions of $\mathrm{Cu}_{\mathrm{x}} \mathrm{S}$ were prepared at $80{ }^{\circ} \mathrm{C}$ by mixing elemental $\mathrm{Cu}$ and $\mathrm{S}$ precursors in the desired stoichiometric molar quantities; each synthesis yielded approximately $5 \mathrm{~g}$ of product, corresponding to a yield of more than $94 \%$. In order to explore the effects of stoichiometry on the thermoelectric properties of $\mathrm{Cu}_{\mathrm{x}} \mathrm{S}$, molar $\mathrm{Cu}: \mathrm{S}$ ratios of 1.00:1, 1.75:1, 1.80:1, and 2.00:1 (these samples will be denoted as S-X where $\mathrm{x}$ denotes the molar ratio of $\mathrm{Cu}$ to $\mathrm{S}$, such as $\mathrm{S}-1.00, \mathrm{~S}-1.75, \mathrm{~S}-1.80$, and $\mathrm{S}-2.00$, respectively) were selected for the formation of the respective compounds, $\mathrm{CuS}, \mathrm{Cu}_{1.75} \mathrm{~S}$, 
$\mathrm{Cu}_{1.80} \mathrm{~S}$, and $\mathrm{Cu}_{2} \mathrm{~S}$, which are some of the well-known forms of copper sulfide. Due to the marked differences between the crystallographic phases of these materials, it was possible to employ XRD to identify the presence of particular $\mathrm{Cu}_{\mathrm{x}} \mathrm{S}$ compounds within each sample powder; diffraction patterns acquired from the four products are presented in Figure 3. With the exception of the sample prepared using a $\mathrm{Cu}: \mathrm{S}$ ratio of $1.80: 1$, which ostensibly comprised a mixture of $\mathrm{Cu}_{1.75} \mathrm{~S}$ and $\mathrm{Cu}_{1.80} \mathrm{~S}$, each diffractogram is consistent with the corresponding JCPDS pattern for the desired stoichiometry of $\mathrm{Cu}_{\mathrm{x}} \mathrm{S}$; for reference, peaks from JCPDS card numbers 06-0464, 23-0958, 47-1748 and 09-0328 have been included as appropriate in Figure 3 to illustrate the standard diffraction patterns of $\mathrm{CuS}, \mathrm{Cu}_{1.75} \mathrm{~S}, \mathrm{Cu}_{1.80} \mathrm{~S}$ and $\mathrm{Cu}_{2} \mathrm{~S}$, respectively. The unwanted presence of $\mathrm{Cu}_{1.75} \mathrm{~S}$ within the $\mathrm{S}-1.80$ sample is unsurprising due to the similar stoichiometries of the two materials, and it should be further acknowledged that no reagents were utilised to ensure phase-selectivity during the synthesis procedure. Indeed, the close agreement between the stoichiometry of the $\mathrm{Cu}_{\mathrm{x}} \mathrm{S}$ product and the molar ratio of the $\mathrm{Cu}$ and $\mathrm{S}$ precursors is a remarkable result, demonstrating that a particular phase of $\mathrm{Cu}_{\mathrm{x}} \mathrm{S}$ may be readily acquired without the use of control measures employed in previous studies. ${ }^{52-54}$ Further, the lattice parameters extracted from the XRD patterns are provided in Table S1 of the Supporting Information; they are consistent with standard values (standard values were obtained from the JCPDS files), supporting the presence of the above phases.

The possible mechanism of the formation of copper sulfide from copper and sulfur powders can be as follows. In the reaction, S powder reacts with hydrazine hydrate forming a complex solution of $\mathrm{S}$ ions. ${ }^{55}$ These as formed $\mathrm{S}$ ions are then rapidly react with $\mathrm{Cu}$ and convert it into copper sulfide. A mild heating of the reaction mixture accelerates the reaction between $\mathrm{S}$ and $\mathrm{Cu}$. Hydrazine hydrate plays an important role in the conversion of $\mathrm{Cu}$ and $\mathrm{S}$ powders into copper sulfide; facilitates the reaction at such low heating temperatures. 

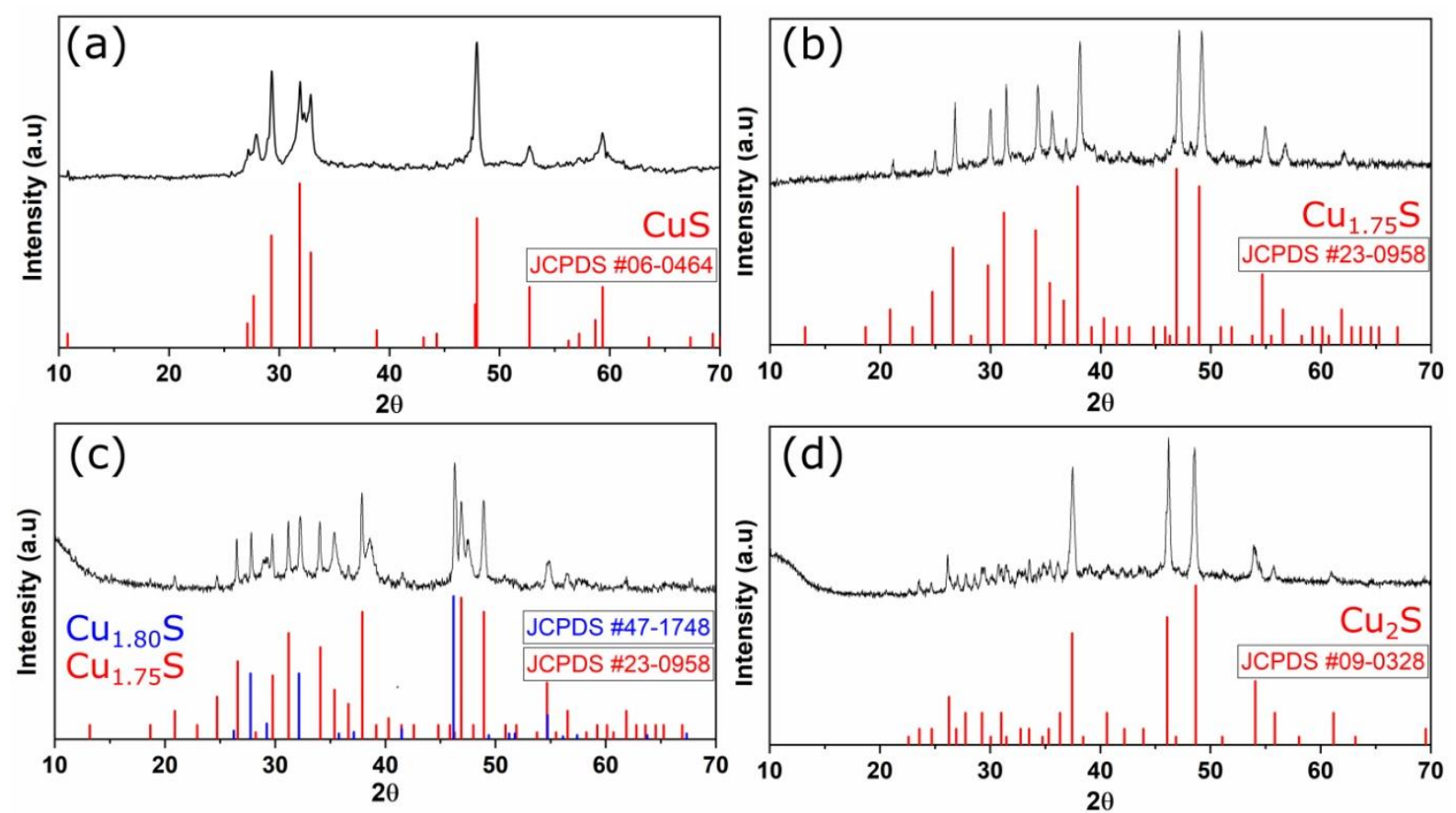

Figure 3. X-ray diffraction patterns of the $\mathrm{Cu}_{\mathrm{x}} \mathrm{S}$ compounds obtained from reaction between

$\mathrm{Cu}$ and $\mathrm{S}$ powders in the ratios (a) 1.00:1 (S-1.00), (b) 1.75:1 (S-1.75), (c) 1.80:1 (S-1.80), and (d) 2.00:1 (S-2.00). 

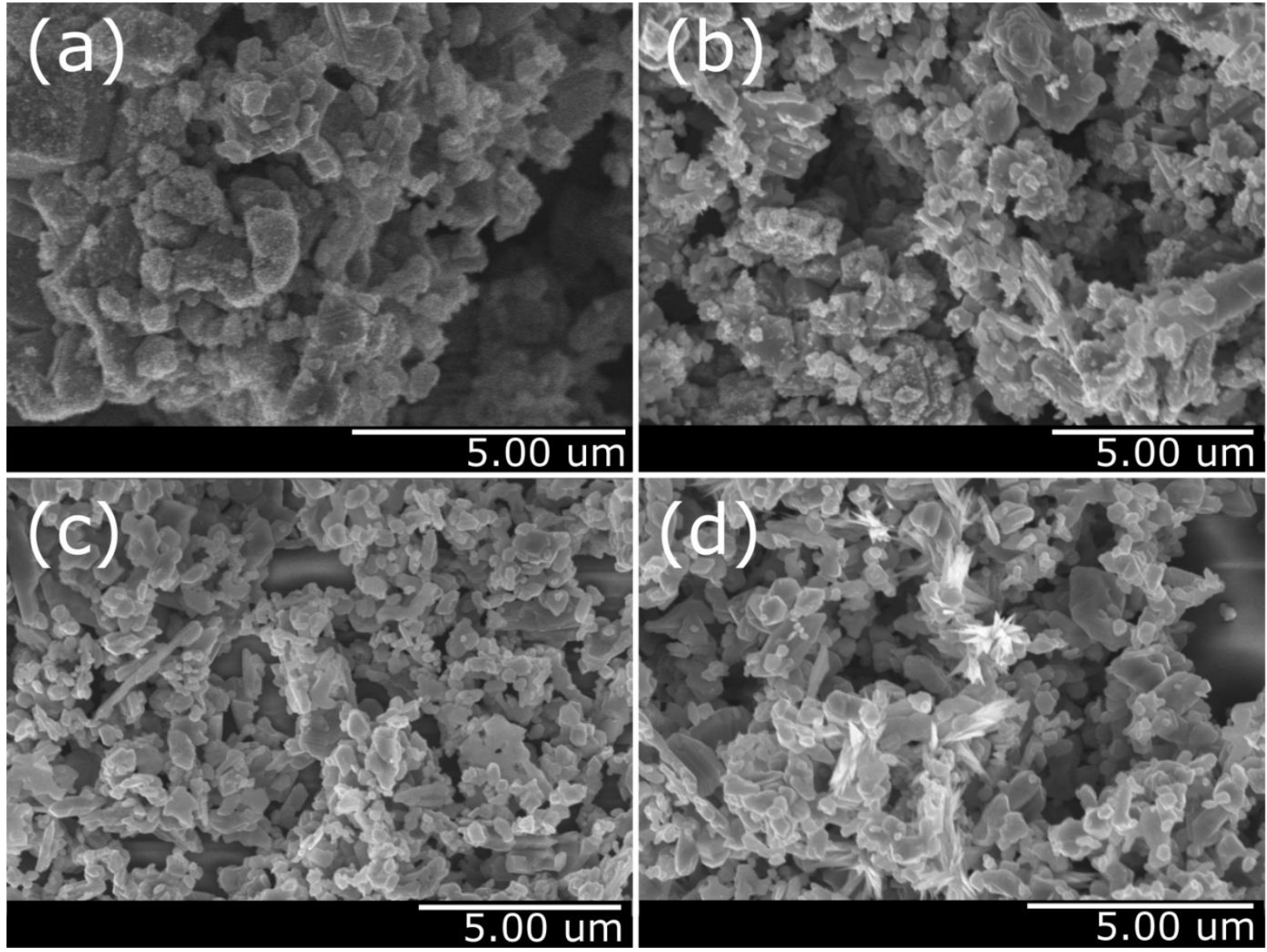

Figure 4. SEM images showing micro-scale particles obtained from the reaction between $\mathrm{Cu}$ and S powders taken in the ratios (a) 1.00:1 (S-1.00), (b) 1.75:1 (S-1.75), (c) 1.80:1 (S-1.80), and (d) 2.00:1 (S-2.00).

Scanning electron microscopy (SEM) images of the $\mathrm{Cu}_{\mathrm{x}} \mathrm{S}$ samples are shown in Figure 4; it is evident from these micrographs that all of the compounds contained a variety of plate-like structures with typical sizes in the range 0.5-2.0 $\mu \mathrm{m}$. Alongside the SEM characterisation, EDX spectra were recorded in order to further verify the bulk chemical composition of each sample powder, as displayed in Figure S1-S2 of the Supporting Information. In accordance with the XRD diffractograms in Figure 3, the estimated $\mathrm{Cu} / \mathrm{S}$ molar ratios from the EDX data are approximately consistent with the expected formulae of the $\mathrm{Cu}_{\mathrm{x}} \mathrm{S}$ products: for the four $\mathrm{Cu} / \mathrm{S}$ molar precursor ratios of $1.00: 1,1.75: 1,1.80: 1$ and 2.00:1, respective molar ratios of 1.09:1, 1.81:1, 1.87:1 and 2.08:1 are obtained from EDX characterisation of the resulting $\mathrm{Cu}_{\mathrm{x}} \mathrm{S}$ compounds. 


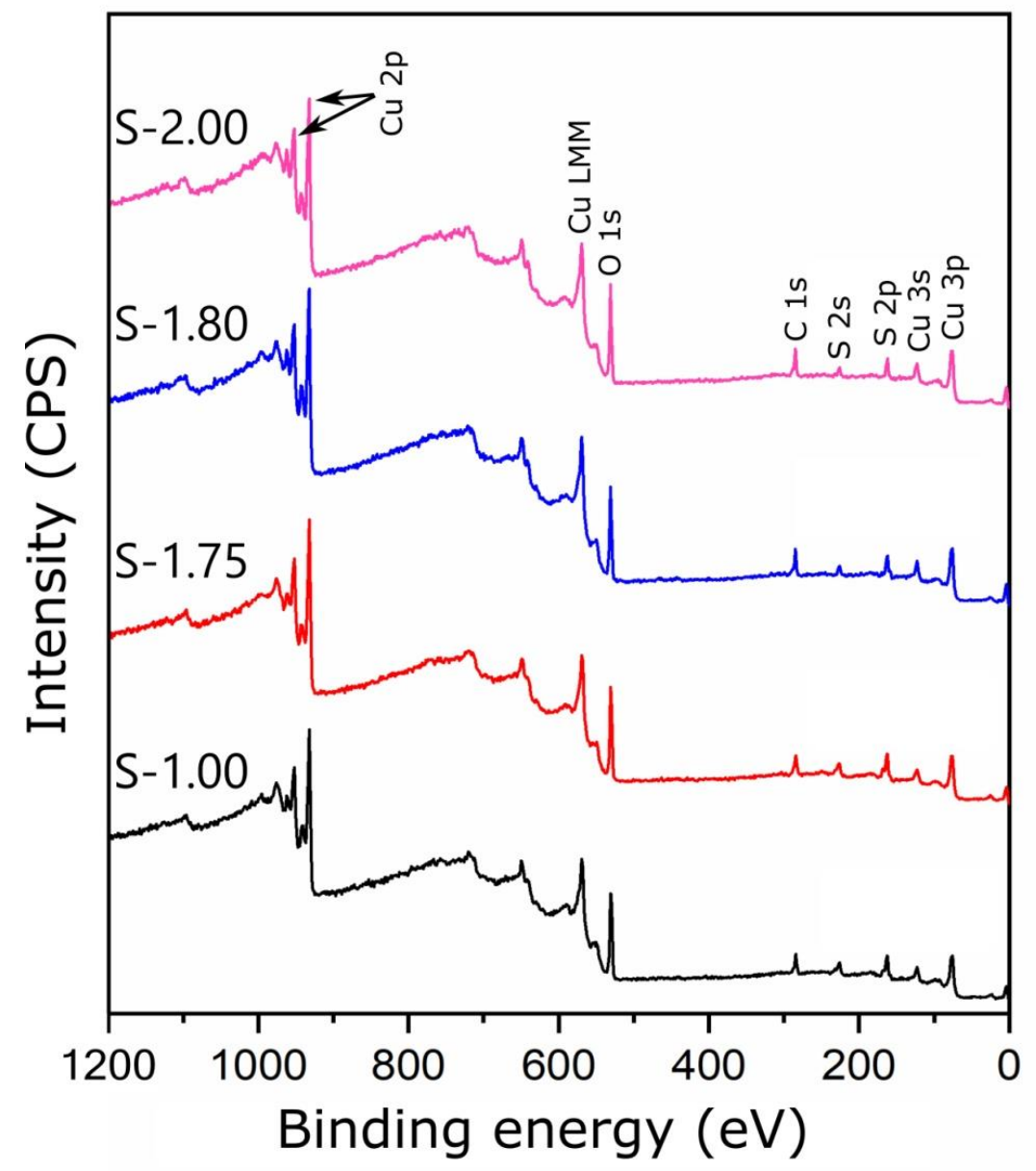

Figure 5. XPS survey spectra from the $\mathrm{Cu}_{\mathrm{x}} \mathrm{S}$ samples over the range $0-1200 \mathrm{eV}$. 


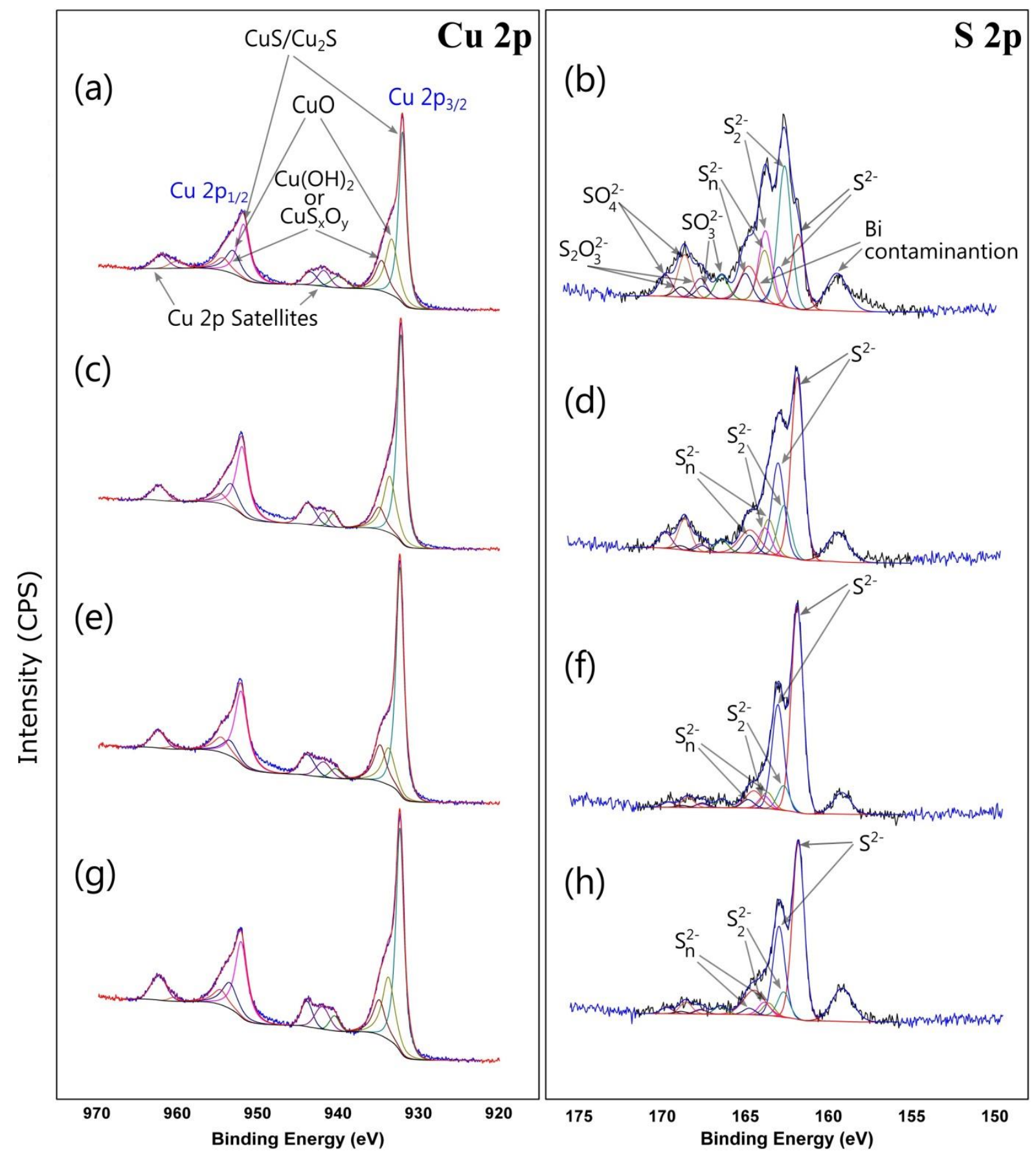

Figure 6. High-resolution XPS measurements of the $\mathrm{Cu}_{\mathrm{x}} \mathrm{S}$ samples, where a, c, e, g are fitted $\mathrm{Cu} 2 \mathrm{p}$ data, and b, d, f, h are fitted S 2p data of S-1.00 (a-b), S-1.75 (c-d), S-1.80 (e-f), and S$2.00(\mathrm{~g}-\mathrm{h})$.

The surface chemistry of the samples was investigated using XPS, including survey spectra of the samples recorded over the binding energy range $0-1200 \mathrm{eV}$ and higher-resolution scans of the $\mathrm{Cu} 2 \mathrm{p}$ and $\mathrm{S} 2 \mathrm{p}$ spectra; these measurements are displayed in Figure 5 and Figure 6, 
with core spectra of C 1s and O 1s provided in Figure S3 of the Supporting Information. The compositional analysis of the $\mathrm{Cu}_{\mathrm{x}} \mathrm{S}$ samples was estimated using XPS data; all the samples have shown $\mathrm{Cu}$ deficient $\mathrm{Cu} / \mathrm{S}$ molar ratios. The $\mathrm{Cu} / \mathrm{S}$ molar ratios of 0.93:1, 1.39:1, 1.48:1, and 1.80:1 are obtained for samples S-1.00, S-1.75, S-1.80, and S-2.00, respectively. In contrast, the EDX data in each case has shown quite near $\mathrm{Cu} / \mathrm{S}$ molar ratios, whereas the values from the XPS are largely deviated from the intended stoichiometry. These XPS based $\mathrm{Cu} / \mathrm{S}$ molar ratio values suggest that the surfaces of the all the samples are either $\mathrm{Cu}$-deficient or rich with S-containing moieties. Further, the $\mathrm{Cu} / \mathrm{S}$ ratio is almost double in $\mathrm{S}-2.00$ sample that of the S-1.00 sample which suggests that the samples contain similar surface concentrations of $\mathrm{Cu}$ vacancies or $\mathrm{S}$-containing moieties.

The measured core-level spectrum of $\mathrm{Cu} 2 \mathrm{p}$ and $\mathrm{S} 2 \mathrm{p}$ in each case is represented by a black line, with coloured Gaussian-Lorentzian fitting components (Figure 6). The $\mathrm{Cu} 2 \mathrm{p}_{3 / 2}$ spectrum peak in all cases is situated at a binding energy of $932.1 \mathrm{eV}$, consistent with previous literature on $\mathrm{CuS} / \mathrm{Cu}_{2} \mathrm{~S} ;{ }^{56-58}$ in addition to these components, there are also impurity signals in all the samples originating from $\mathrm{CuO}$ and $\mathrm{Cu}(\mathrm{OH})_{2} / \mathrm{CuS}_{\mathrm{x}} \mathrm{O}_{\mathrm{y} .}{ }^{10}$ It is quite peculiar that there is no change in the position of the main peak of $\mathrm{Cu} 2 \mathrm{p}_{3 / 2}$ from the compositional variations from $\mathrm{CuS}$ (Sample S-1.00) to $\mathrm{Cu}_{2} \mathrm{~S}$ (Sample S-2.00), which suggests that there might not be any changes in the nature of $\mathrm{Cu}$ in all the compounds. In fact, many XPS studies have reported the oxidation state of $\mathrm{Cu}$ in $\mathrm{CuS}$ as $\mathrm{Cu}(\mathrm{I})$ not $\mathrm{Cu}(\mathrm{II}),{ }^{56,59}$ which seemingly contradicts the crystal structure based formulation and octet rule. A couple of studies have suggested the possible bonding structures of the form of $\left(\mathrm{Cu}^{1+}\right)_{3}\left(\mathrm{~S}_{2}{ }^{2-}\right)\left(\mathrm{S}^{1-}\right)$ or $\left(\mathrm{Cu}^{1+}\right)_{3}\left(\mathrm{~S}_{2}{ }^{1-}\right)\left(\mathrm{S}^{2-}\right)$ in $\mathrm{CuS}$ and hence found monovalent copper in it, ${ }^{57,60}$ whilst other studies have reported the presence of both $\mathrm{Cu}(\mathrm{I})$ and $\mathrm{Cu}(\mathrm{II})$ in $\mathrm{CuS}$ with a bonding structure of the form of $\left(\mathrm{Cu}^{+}\right)_{2} \mathrm{Cu}^{2+}\left(\mathrm{S}_{2}\right)^{2-} \mathrm{S}^{2-} \cdot{ }^{57}$ However, the oxidation state of $\mathrm{Cu}$ in $\mathrm{CuS}$ is still under debate. ${ }^{57}$ All the compounds show weak satellites over the energy range 940-945 eV, which 
are characteristic of $\mathrm{Cu}(\mathrm{II})$ chemical environments arising from $\mathrm{CuO}, \mathrm{Cu}(\mathrm{OH})_{2}$ and/or $\mathrm{CuSO}_{4}$. The S $2 \mathrm{p}_{3 / 2}$ peaks of the $\mathrm{S} 2 \mathrm{p}$ doublets include a predominant component at $161.8 \mathrm{eV}$ that can be assigned to sulfide $\left(\mathrm{S}^{2-}\right)$ ions in the $\mathrm{CuS}$ lattice, alongside significant contributions from disulfide $\left(\mathrm{S}_{2}{ }^{2-}\right)$ and polysulfide $\left(\mathrm{S}_{\mathrm{n}}{ }^{2-}\right)$ environments with $2 \mathrm{p}_{3 / 2}$ components centred at $162.7 \mathrm{eV}$ and $163.6 \mathrm{eV}$, respectively. ${ }^{61}$ Additionally, S 2p doublets appearing in the higher binding energy range of $166.4-167.7 \mathrm{eV}$ can be assigned to $\mathrm{SO}_{3}{ }^{2-}, \mathrm{SO}_{4}{ }^{2-}$, and $\mathrm{S}_{2} \mathrm{O}_{3}{ }^{2-}$ related moieties, ${ }^{61,62}$ while a common signal at approximately $159.5 \mathrm{eV}$ is likely attributable $\mathrm{Bi}$ (III) contamination originating from the pellet press process. The pellet press was previously used for Bi based compounds for several times. So, it is believed that the contamination could be from previous materials that were pressed, and also, it can be a contaminant in the $\mathrm{Cu}$ or $\mathrm{S}$ precursors. Notably, the $S^{2-}$ signal of the S-1.00 sample is proportionally weaker than the equivalent component of the other samples while the $\mathrm{S}_{2}{ }^{2-}$ doublet is correspondingly more pronounced; these features indicate that both $\mathrm{S}^{2-}$ and $\mathrm{S}_{2}{ }^{2-}$ environments were prevalent in the S-1.00 sample, and the 1:2 area ratio of the $\mathrm{S}^{2-}$ and $\mathrm{S}_{2}{ }^{2-}$ components is consistent with the reported structure of covellite $\mathrm{CuS} .{ }^{59}$

As shown in Figure S3 of the Supporting Information, all of the oxygen-containing chemical environments identified in the spectra displayed in Figure 6 produced corresponding contributions to the $\mathrm{O} 1 \mathrm{~s}$ spectrum of each sample. As the reactions were carried out without any inert atmosphere, it is likely that formation of these surface groups occurred during the synthesis of the copper sulfide compounds. Nevertheless, as it is clear from the XRD and EDX measurements provided in Figure 3 and Figure S1-S2, respectively, that the bulk materials comprised negligible amounts of these contaminating compounds, one may conclude that they were present exclusively at the surface of each sample and contributed significantly to the XPS spectra due to the high surface-sensitivity of this technique. $^{10}$ 


\section{Evaluation of Thermoelectric Properties}

As shown in Figure 7, the Seebeck coefficient $(S)$, electrical conductivity $(\sigma)$ and thermoelectric power factor $(P F)$ of $\mathrm{Cu}_{\mathrm{x}} \mathrm{S}$ were strongly dependent on the stoichiometric ratio between $\mathrm{Cu}$ and $\mathrm{S}$. Over the investigated temperature range, $S$ measurements from $\mathrm{Cu}_{2} \mathrm{~S}$ were approximately nine times higher than the corresponding values from $\mathrm{CuS}$, while $\mathrm{Cu}_{\mathrm{x}} \mathrm{S}$ compounds with $\mathrm{x}=1.75,1.80$, and 2.00 yielded a threefold increase in $S$ relative to $\mathrm{CuS}$. The observed room temperature $S$ values of $\mathrm{Cu}_{\mathrm{x}} \mathrm{S}$ samples are $10.5 \mu \mathrm{V} \mathrm{K}^{-1}, 25.1 \mu \mathrm{V} \mathrm{K}^{-1}, 30.2 \mu \mathrm{V}$ $\mathrm{K}^{-1}$, and $91.6 \mu \mathrm{V} \mathrm{K}^{-1}$ for $\mathrm{x}=1.00,1.75,1.80$, and 2.00, respectively. Meanwhile, the changes in the electrical conductivity are opposite in nature where it was observed decreasing from $\mathrm{CuS}$ to $\mathrm{Cu}_{2} \mathrm{~S}$. This kind of systematic increase in the Seebeck coefficient and decrease in the electrical conductivity with evolution of copper sulfide from $\mathrm{CuS}$ to $\mathrm{Cu}_{2} \mathrm{~S}$ has been well reported in the previous studies. ${ }^{13,63}$ The typical $S$ value reported in case of $\mathrm{CuS}$ is $10-12 \mu \mathrm{V}$ $\mathrm{K}^{-1},{ }^{39,64,65}$ in $\mathrm{Cu}_{1.75} \mathrm{~S}, 15-20 \mu \mathrm{V} \mathrm{K}^{-1},{ }^{45,66}$ and in case of $\mathrm{Cu}_{1.80} \mathrm{~S}$, it is about $15-30 \mu \mathrm{V} \mathrm{K}^{-1},{ }^{13,34}$, 39,42 but in case of $\mathrm{Cu}_{2} \mathrm{~S}$, the reported $S$ value has a wide range from $80 \mu \mathrm{V} \mathrm{K}^{-1}$ to $300 \mu \mathrm{V} \mathrm{K}-$ $1.10,35,67,68$ The measured values of the present work, by and large, are similar to most of the previous studies in the presently measured temperature range.

A brief explanation on the reason behind such a wide variations in the $S$ values in $\mathrm{Cu}_{2} \mathrm{~S}$ is discussed with the help of previous literature. A perfectly stoichiometric $\mathrm{Cu}_{2} \mathrm{~S}$ is thought to be an intrinsic semiconductor but experimentally it always shows p-type electrical properties. ${ }^{39}$ The p-type electrical conductivity of the $\mathrm{Cu}_{2} \mathrm{~S}$ is predicted to be due to $\mathrm{Cu}$ vacancies in the compound, ${ }^{39}$ as each $\mathrm{Cu}$ vacancy creates a hole inside the material, the hole concentration and associated p-type conductivity increases as a function of the density of vacancies within the material (the electrical conductivity is directly related to the number of charge carriers according to the equation $\sigma=n e \mu$, where $n, e, \mu$ are the number, charge, and mobility of the carriers). For this reason, varying the concentration of vacancies in a $\mathrm{Cu}_{\mathrm{x}} \mathrm{S}$ 
sample has a considerable influence on the Seebeck coefficient of the material. ${ }^{10,63,67}$ In general, the Seebeck coefficient $(S)$ of a $\mathrm{Cu}_{\mathrm{x}} \mathrm{S}$ compound diminishes as the hole concentration (n) is increased, with the relationship between these quantities described by the Mott formula ${ }^{69}$

$$
S=\frac{8 \pi^{2} k_{B}^{2}}{3 e h^{2}} m^{*} T\left(\frac{\pi}{3 n}\right)^{2 / 3}
$$

where $k_{B}, h, e$ and $m^{*}$ denote the Boltzmann constant, Planck's constant, and the charge and effective mass of valence holes, respectively.

Although there was conversely little variation between the $P F$ measurements of $\mathrm{CuS}$, $\mathrm{Cu}_{1.75} \mathrm{~S}$ and $\mathrm{Cu}_{1.80} \mathrm{~S}$, with all three samples exhibiting $P F$ values in the range $30-38 \mu \mathrm{W} \mathrm{m}^{-1}$ $\mathrm{K}^{-2}, \mathrm{Cu}_{2} \mathrm{~S}$ produced a significantly greater power factor, reaching $84 \mu \mathrm{W} \mathrm{m} \mathrm{m}^{-1} \mathrm{~K}^{-2}$ at $100{ }^{\circ} \mathrm{C}$. In combination, the relative $S$ and $P F$ characteristics of the four samples indicate that the $\mathrm{Cu}$ rich $\mathrm{Cu}_{\mathrm{x}} \mathrm{S}$ is potentially beneficial for thermoelectric applications, with $\mathrm{Cu}_{2} \mathrm{~S}$ offering $S$ and $P F$ values of $91 \mu \mathrm{V} \mathrm{K}^{-1}$ and $58 \mu \mathrm{W} \mathrm{m} \mathrm{m}^{-1} \mathrm{~K}^{-2}$, respectively, at room temperature; these measurements are consistent with comparable literature estimates for $\mathrm{Cu}_{2} \mathrm{~S}$ in the presently measured temperature range. Typical range of $P F$ reported for $\mathrm{Cu}_{2} \mathrm{~S}$ are about $30-100 \mu \mathrm{W} \mathrm{m}^{-1}$ $\mathrm{K}^{-2}$ around room temperature and high $P F$ of $250-300 \mu \mathrm{W} \mathrm{m} \mathrm{m}^{-1} \mathrm{~K}^{-2}$ have been reported at higher temperatures (above $700 \mathrm{~K}$ ). ${ }^{10,35,68,70}$ While the measured variations in $S$ and $P F$ as a function of chemical composition are similarly representative of trends reported elsewhere. ${ }^{10}$, 13,35 

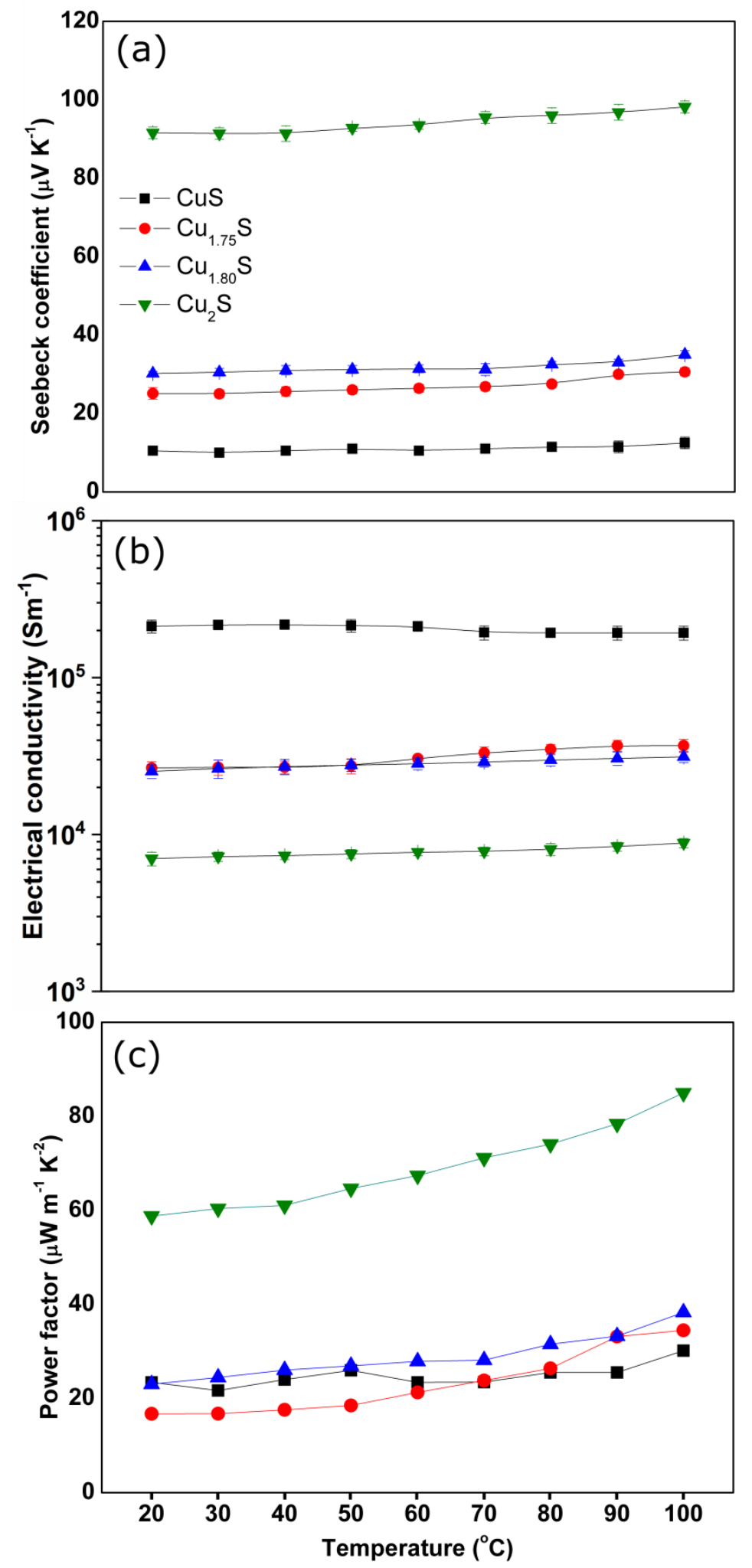

Figure 7. Measurements of the Seebeck coefficient for the four $\mathrm{Cu}_{\mathrm{x}} \mathrm{S}$ samples (a), alongside corresponding measurements of the electrical conductivity (b) and thermoelectric power factor (c) with respect to temperature. 


\section{Thermoelectric Device Characterization}

In order to explore the thermoelectric current-voltage characteristics of a $\mathrm{Cu}_{\mathrm{x}} \mathrm{S}$-based thermoelectric generator, the electrical response of an interconnected arrangement of ten $\mathrm{Cu}_{\mathrm{x}} \mathrm{S}$ pellets was investigated under the application of different temperature gradients. For this purpose, $\mathrm{Cu}_{2} \mathrm{~S}$ was selected due to the superior Seebeck coefficient which is important to generate a good output voltage from the device, and thermoelectric power factor it exhibited relative to other $\mathrm{Cu}_{\mathrm{x}} \mathrm{S}$ compounds; the constituent $\mathrm{Cu}_{2} \mathrm{~S}$ pellets of the prototype thermoelectric module are pictured in Figure 8a, alongside photographs of the completed device in Figure $8 \mathrm{~b}$ and $\mathrm{c}$.

After heating the underside of generator to temperatures in the range $40-70{ }^{\circ} \mathrm{C}$, the thermoelectric open-circuit potential $\left(V_{\mathrm{o}}\right)$ generated between all the ten $\mathrm{Cu}_{2} \mathrm{~S}$ pellets was measured in addition to the short-circuit current $\left(I_{0}\right)$ produced by the device; these measurements are plotted in Figure $8 \mathrm{~d}$. Both $V_{o}$ and $I_{o}$ increased markedly as the base temperature of the device was incrementally raised, reaching respective values of $30.9 \mathrm{mV}$ and $0.44 \mathrm{~mA}$ at $70{ }^{\circ} \mathrm{C}$; producing a power output of $3.4 \mu \mathrm{W}$. Further, the surface power density and volume power density have been estimated by considering total cross-sectional area and volume of the thermoelectric elements (copper sulfide pellets) respectively, and the corresponding plots are provided in Figure S4 of the Supporting Information. The observed maximum values of surface and volume power density are $1.7 \mu \mathrm{W} \mathrm{cm}{ }^{-2}$ and $4.9 \mu \mathrm{W} \mathrm{cm}{ }^{-3}$ at $70{ }^{\circ} \mathrm{C}$, respectively. The power output characteristics are comparable to literature estimates for materials such as Te/polymer composites, expensive polymers such as poly $(3,4-$ ethylenedioxythiophene) polystyrene sulfonate (PEDOT:PSS), $\mathrm{TiS}_{2}, \mathrm{CuSe}$, and other metal chalcogenide based devices, indicating that $\mathrm{Cu}_{2} \mathrm{~S}$ could serve as a potentially competitive basis for thermoelectric devices. ${ }^{71-76}$ Also, as the new type of flexible thermoelectric devices 
are becoming more popular, ${ }^{76-78} \mathrm{Cu}_{\mathrm{x}} \mathrm{S}$ can be utilized to replace expensive compounds in combination with polymer/organic compounds. ${ }^{77}$

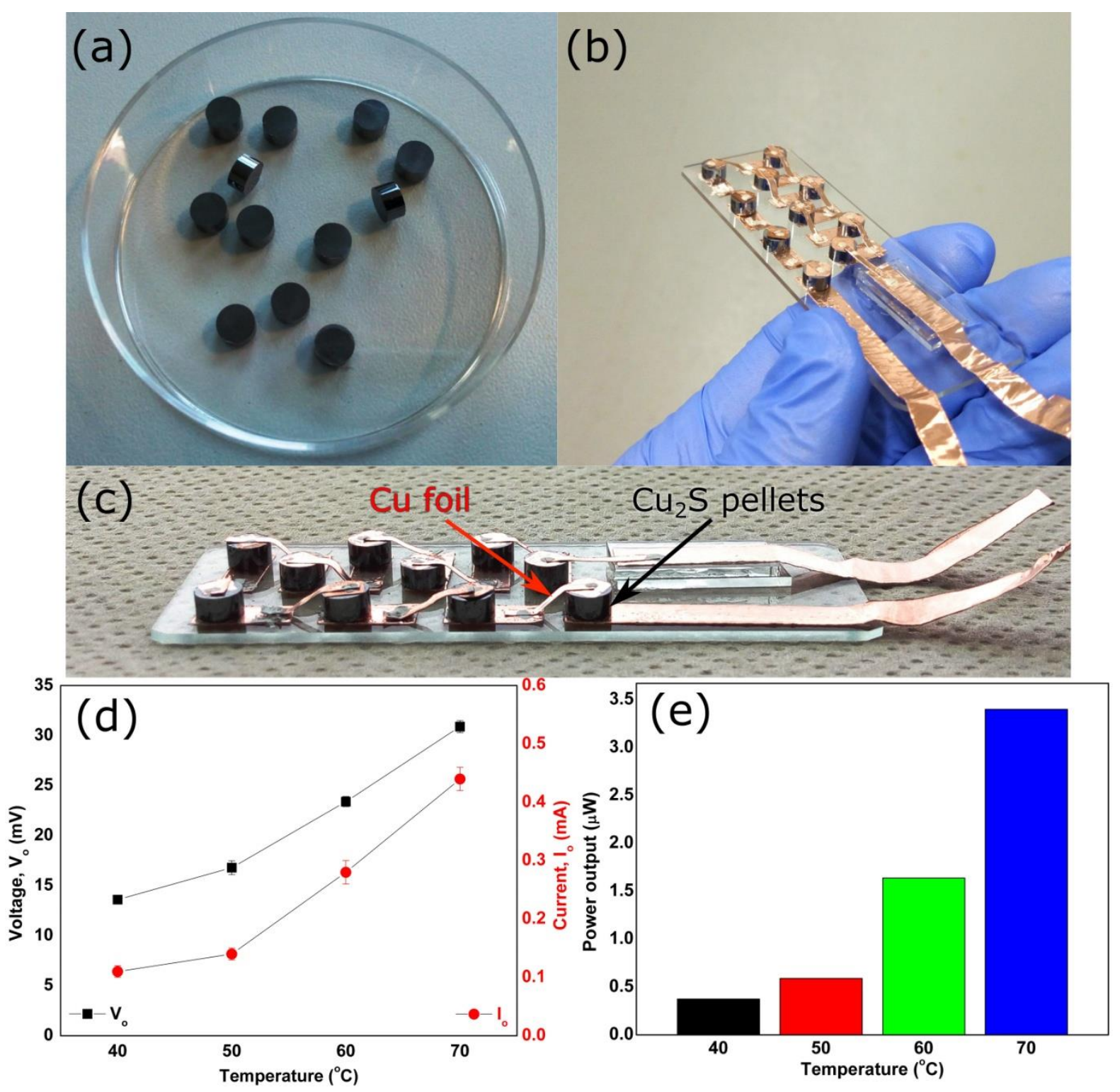

Figure 8. Photographs showing the $\mathrm{Cu}_{2} \mathrm{~S}$ pellets (a) employed in a prototype thermoelectric generator module comprising ten $\mathrm{Cu}_{2} \mathrm{~S}$ pellets (b-c), in addition to the measured open-circuit voltage $\left(V_{o}\right)$ and short-circuit current $\left(I_{o}\right)$ of the device at different hot-side temperatures (d) and the corresponding values of peak power output estimated from Eq. 3 (e). 


\section{CONCLUSIONS}

The present work shows that the bulk copper sulfide samples could be synthesized from a facile and low-cost synthesis method using constituent elements. The $\mathrm{Cu}: \mathrm{S}$ molar ratio in the product could then be tuned from 1.00:1 to 2.00:1, by simply varying the masses of starting elemental $\mathrm{Cu}$ and $\mathrm{S}$ powders without the need of specific chemicals or reagents to control the reaction process. Moreover, the present protocol can be easily adapted and scaled-up for a large-scale production of copper sulfides by increasing volume of the reaction. A systematic variation in the thermoelectric properties of the compounds with respect to their $\mathrm{Cu} / \mathrm{S}$ molar ratio has been observed which is consistent with the previous literature. The impurities in the materials possibly originate from oxidation of the particles during open-air synthesis, and hence it is predicted that higher purity could be achieved by carrying out the synthesis procedure under inert atmosphere. Hydrazine hydrate was preferred in the present protocol as its combination with sulfur works better and sulfur readily dissolves in it; assists quick release of sulfur ions and hence fast reaction. ${ }^{55,65}$ Assuming a linear relationship between thermoelectric potential and current, a thermoelectric generator module comprised of ten ptype copper sulfide pellets was capable of producing an estimated maximum power output of $3.4 \mu \mathrm{W}$ at $70{ }^{\circ} \mathrm{C}$, demonstrating that the material offers a promising alternative to the toxic and expensive materials used in typical commercial thermoelectric devices. As the copper sulfide-based compounds exhibit unique electronic properties as they exhibit very low thermal conductivity of less than $\sim 0.5 \mathrm{~W} \mathrm{~m}^{-1} \mathrm{~K}^{-1}$ despite their good electrical conductivity, ${ }^{10}$, ${ }^{12}$ which is an important factor to achieve higher thermal gradients in the generators; they are also attractive candidates for several other applications such as in solar cells, energy storage, and photocatalysis. ${ }^{79}$ The present synthesis protocol can in general be applied to produce other metal sulfide materials and help make the fabrication process more economical. 


\section{SUPPORTING INFORMATION}

The Supporting Information is available free of charge at http://pubs.acs.org/

Lattice parameter values; EDX data and XPS spectra ( $\mathrm{C}$ 1s and $\mathrm{O}$ 1s) of $\mathrm{Cu}_{\mathrm{x}} \mathrm{S}$ samples; output power density data of the test generator.

\section{ACKNOWLEDGEMENTS}

Authors are thankful to the Welsh Government (EU European Regional Development Fund) for funding the RICE (Reducing Industrial Carbon Emission) project (Grant Number: 81435). Authors would like to acknowledge the assistance provided by Swansea University College of Engineering AIM Facility, which was funded in part by the EPSRC (EP/M028267/1), the European Regional Development Fund through the Welsh Government (80708) and the Ser Solar project via Welsh Government.

\section{CONFLICT OF INTEREST}

The authors declare no competing financial interest.

\section{REFERENCES}

1. Kulkarni, P.; Nataraj, S. K.; Balakrishna, R. G.; Nagaraju, D. H.; Reddy, M. V., Nanostructured binary and ternary metal sulfides: synthesis methods and their application in energy conversion and storage devices. J. Mater. Chem. A 2017, 5 (42), 22040-22094. DOI 10.1039/C7TA07329A

2. Fu, G.; Lee, J.-M., Ternary metal sulfides for electrocatalytic energy conversion. J. Mater. Chem. A 2019, 7 (16), 9386-9405. DOI 10.1039/C9TA01438A

3. Chandrasekaran, S.; Yao, L.; Deng, L.; Bowen, C.; Zhang, Y.; Chen, S.; Lin, Z.; Peng, F.; Zhang, P., Recent advances in metal sulfides: from controlled fabrication to electrocatalytic, photocatalytic and photoelectrochemical water splitting and beyond. Chem. Soc. Rev. 2019, 48 (15), 4178-4280. DOI 10.1039/C8CS00664D

4. Moon, D. G.; Rehan, S.; Yeon, D. H.; Lee, S. M.; Park, S. J.; Ahn, S.; Cho, Y. S., A review on binary metal sulfide heterojunction solar cells. Sol. Energy Mater. Sol. Cells 2019, 200, 109963. DOI 10.1016/j.solmat.2019.109963

5. Song, W.-S.; Yang, H., Efficient White-Light-Emitting Diodes Fabricated from Highly Fluorescent Copper Indium Sulfide Core/Shell Quantum Dots. Chem. Mater. 2012, 24 (10), 19611967. DOI 10.1021/cm300837z 
6. Yang, D.; Cho, I.; Kim, D.; Lim, M. A.; Li, Z.; Ok, J. G.; Lee, M.; Park, I., Gas Sensor by Direct Growth and Functionalization of Metal Oxide/Metal Sulfide Core-Shell Nanowires on Flexible Substrates. ACS Appl. Mater. Interfaces 2019, 11 (27), 24298-24307. DOI 10.1021/acsami.9b06951

7. Xu, X.; Rout, C. S.; Yang, J.; Cao, R.; Oh, P.; Shin, H. S.; Cho, J., Freeze-dried WS2 composites with low content of graphene as high-rate lithium storage materials. J. Mater. Chem. A 2013, 1 (46), 14548-14554. DOI 10.1039/C3TA13329J

8. Shaikh, S.; Rabinal, M. K., Rapid ambient growth of copper sulfide microstructures: Binder free electrodes for supercapacitor. J. Energy Storage 2020, 28, 101288. DOI 10.1016/j.est.2020.101288

9. Hsu, Y.-K.; Chen, Y.-C.; Lin, Y.-G., Synthesis of copper sulfide nanowire arrays for highperformance supercapacitors. Electrochimica Acta 2014, 139, 401-407. DOI 10.1016/j.electacta.2014.06.138

10. Burton, M. R.; Mehraban, S.; McGettrick, J.; Watson, T.; Lavery, N. P.; Carnie, M. J., Earth abundant, non-toxic, 3D printed Cu2-xS with high thermoelectric figure of merit. J. Mater. Chem. A 2019, 7 (44), 25586-25592. DOI 10.1039/C9TA10064D

11. Meng, Q.-L.; Kong, S.; Huang, Z.; Zhu, Y.; Liu, H.-C.; Lu, X.; Jiang, P.; Bao, X., Simultaneous enhancement in the power factor and thermoelectric performance of copper sulfide by $\ln 2 \mathrm{~S} 3$ doping. J. Mater. Chem. A 2016, 4 (32), 12624-12629. DOI 10.1039/C6TA03780A

12. Mulla, R.; Rabinal, M. H. K., Copper Sulfides: Earth-Abundant and Low-Cost Thermoelectric Materials. Energy Technol. 2019, 7 (7), 1800850. DOI 10.1002/ente.201800850

13. Qiu, P.; Zhu, Y.; Qin, Y.; Shi, X.; Chen, L., Electrical and thermal transports of binary copper sulfides CuxS with $x$ from 1.8 to 1.96. APL Mater. 2016, 4 (10), 104805. DOI 10.1063/1.4953439

14. Goel, S.; Chen, F.; Cai, W., Synthesis and Biomedical Applications of Copper Sulfide Nanoparticles: From Sensors to Theranostics. Small 2014, 10 (4), 631-645. DOI 10.1002/smll.201301174

15. Lesyuk, R.; Klein, E.; Yaremchuk, I.; Klinke, C., Copper sulfide nanosheets with shapetunable plasmonic properties in the NIR region. Nanoscale 2018, 10 (44), 20640-20651. DOI 10.1039/C8NR06738D

16. Liu, Y.; Liu, M.; Swihart, M. T., Plasmonic Copper Sulfide-Based Materials: A Brief Introduction to Their Synthesis, Doping, Alloying, and Applications. J. Phys. Chem. C 2017, 121 (25), 13435-13447. DOI 10.1021/acs.jpcc.7b00894

17. Wang, G.; Li, C.; Shan, H., Highly Efficient Metal Sulfide Catalysts for Selective Dehydrogenation of Isobutane to Isobutene. ACS Catal. 2014, 4 (4), 1139-1143. DOI $10.1021 / \operatorname{cs} 5000944$

18. Jones, D. R.; Phillips, R.; Gannon, W. J. F.; Rome, B.; Warwick, M. E. A.; Dunnill, C. W., Photocapacitive CdS/WOx nanostructures for solar energy storage. Sci. Rep. 2019, 9 (1), 11573. DOI 10.1038/s41598-019-48069-5

19. Escalera-López, D.; Griffin, R.; Isaacs, M.; Wilson, K.; Palmer, R. E.; Rees, N. V., Electrochemical sulfidation of WS2 nanoarrays: Strong dependence of hydrogen evolution activity on transition metal sulfide surface composition. Electrochem. commun. 2017, 81, 106-111. DOI 10.1016/j.elecom.2017.06.016

20. Ohta, T.; Asakura, S.; Yamaguchi, M.; Kamiya, N.; Gotgh, N.; Otagawa, T., Photochemical and thermoelectric utilization of solar energy in a hybrid water-splitting system. Int. J. Hydrog. Energy 1976, 1 (2), 113-116. DOI 10.1016/0360-3199(76)90063-X

21. Zhang, X.; Gao, W.; Su, X.; Wang, F.; Liu, B.; Wang, J.-J.; Liu, H.; Sang, Y., Conversion of solar power to chemical energy based on carbon nanoparticle modified photo-thermoelectric generator and electrochemical water splitting system. Nano Energy 2018, 48, 481-488. DOI 10.1016/j.nanoen.2018.03.055

22. Phillips, R.; Dunnill, Charles W., Zero gap alkaline electrolysis cell design for renewable energy storage as hydrogen gas. RSC Adv. 2016, 6 (102), 100643-100651. DOI 10.1039/C6RA22242K 
23. Jones, D. R.; Al-Masry, W. A.; Dunnill, Charles W., Hydrogen-enriched natural gas as a domestic fuel: an analysis based on flash-back and blow-off limits for domestic natural gas appliances within the UK. Sustain. Energy Fuels 2018, 2 (4), 710-723. DOI 10.1039/C7SE00598A

24. Phillips, R.; Edwards, A.; Rome, B.; Jones, D. R.; Dunnill, C. W., Minimising the ohmic resistance of an alkaline electrolysis cell through effective cell design. Int. J. Hydrog. Energy 2017, 42 (38), 23986-23994. DOI 10.1016/j.ijhydene.2017.07.184

25. Mulla, R.; Dunnill, C. W., Powering the Hydrogen Economy from Waste Heat: A Review of Heat-to-Hydrogen Concepts. ChemSusChem 2019, 12 (17), 3882-3895. DOI 10.1002/cssc.201901426

26. Freer, R.; Powell, A. V., Realising the potential of thermoelectric technology: a Roadmap. J. Mater. Chem. C 2020, 8 (2), 441-463. DOI 10.1039/C9TC05710B

27. LeBlanc, S.; Yee, S. K.; Scullin, M. L.; Dames, C.; Goodson, K. E., Material and manufacturing cost considerations for thermoelectrics. Renew. Sust. Energ. Rev. 2014, 32, 313-327. DOI 10.1016/j.rser.2013.12.030

28. Yee, S. K.; LeBlanc, S.; Goodson, K. E.; Dames, C., \$ per W metrics for thermoelectric power generation: beyond ZT. Energy Environ. Sci. 2013, 6 (9), 2561-2571. DOI 10.1039/C3EE41504J

29. Grocholski, B., Lower-cost thermoelectrics. Science 2019, 365 (6460), 1414-1414. DOI 10.1126/science.365.6460.1414-b

30. Mao, J.; Zhu, H.; Ding, Z.; Liu, Z.; Gamage, G. A.; Chen, G.; Ren, Z., High thermoelectric cooling performance of $\mathrm{n}$-type Mg\&lt;sub\&gt;3\&lt;/sub\&gt;Bi\&lt;sub\&gt;2\&lt;/sub\&gt;-based materials. Science 2019, 365 (6452), 495. DOI 10.1126/science.aax7792

31. Zhang, Y.; Rhee, K. Y.; Park, S.-J., Facile design of a domestic thermoelectric generator by tailoring the thermoelectric performance of volume-controlled expanded graphite/PVDF composites. Compos. B. Eng. 2019, 176, 107234. DOI 10.1016/j.compositesb.2019.107234

32. Mulla, R.; Rabinal, M. K., Defect-Controlled Copper lodide: A Promising and Ecofriendly Thermoelectric Material. Energy Technol. 2018, 6 (6), 1178-1185. DOI 10.1002/ente.201700708

33. Mulla, R.; Dunnill, C. W., Graphite-loaded cotton wool: A green route to highly-porous and solid graphite pellets for thermoelectric devices. Comp. Commun. 2020, 20, 100345. DOI 10.1016/j.coco.2020.04.011

34. Ge, Z.-H.; Zhang, Y.-X.; Song, D.; Chong, X.; Qin, P.; Zheng, F.; Feng, J.; Zhao, L.-D., Excellent $\mathrm{ZT}$ achieved in $\mathrm{Cu} 1.8 \mathrm{~S}$ thermoelectric alloys through introducing rare-earth trichlorides. J. Mater. Chem. A 2018, 6 (29), 14440-14448. DOI 10.1039/C8TA03195A

35. Zhao, L.; Wang, X.; Fei, F. Y.; Wang, J.; Cheng, Z.; Dou, S.; Wang, J.; Snyder, G. J., High thermoelectric and mechanical performance in highly dense Cu2-xS bulks prepared by a meltsolidification technique. J. Mater. Chem. A 2015, 3 (18), 9432-9437. DOI 10.1039/C5TA01667C

36. Tang, H.; Sun, F.-H.; Dong, J.-F.; Asfandiyar; Zhuang, H.-L.; Pan, Y.; Li, J.-F., Graphene network in copper sulfide leading to enhanced thermoelectric properties and thermal stability. Nano Energy 2018, 49, 267-273. DOI 10.1016/j.nanoen.2018.04.058

37. Tang, H.; Zhuang, H.-L.; Cai, B.; Asfandiyar; Dong, J.; Sun, F.-H.; Li, J.-F., Enhancing the thermoelectric performance of $\mathrm{Cu} 1.8 \mathrm{~S}$ by $\mathrm{Sb} / \mathrm{Sn}$ co-doping and incorporating multiscale defects to scatter heat-carrying phonons. J. Mater. Chem. C 2019, 7 (14), 4026-4031. DOI 10.1039/C9TC01096C 38. Zhang, Y.-x.; Feng, J.; Ge, Z.-h., High thermoelectric performance realized in porous Cu1.8S based composites by $\mathrm{Na} 2 \mathrm{~S}$ addition. Mater. Sci. Semicond. Process. 2020, 107, 104848. DOI 10.1016/j.mssp.2019.104848

39. Dennler, G.; Chmielowski, R.; Jacob, S.; Capet, F.; Roussel, P.; Zastrow, S.; Nielsch, K.; Opahle, I.; Madsen, G. K. H., Are Binary Copper Sulfides/Selenides Really New and Promising Thermoelectric Materials? Adv. Energy Mater. 2014, 4 (9), 1301581. DOI 10.1002/aenm.201301581

40. Powell, A. V., Recent developments in Earth-abundant copper-sulfide thermoelectric materials. J. Appl. Phys. 2019, 126 (10), 100901. DOI 10.1063/1.5119345

41. Mao, T.; Qiu, P.; Liu, J.; Du, X.; Hu, P.; Zhao, K.; Ren, D.; Shi, X.; Chen, L., Good stability and high thermoelectric performance of Fe doped Cu1.80S. Phys. Chem. Chem. Phys. 2020, 22, 7374. DOI 10.1039/DOCP00733A 
42. Ge, Z.-H.; Zhang, B.-P.; Chen, Y.-X.; Yu, Z.-X.; Liu, Y.; Li, J.-F., Synthesis and transport property of $\mathrm{Cu} 1.8 \mathrm{~S}$ as a promising thermoelectric compound. Chem. Commun. 2011, 47 (47), 1269712699. DOI 10.1039/C1CC16368J

43. Gu, S.-W.; Zhang, Y.-X.; Guo, J.; Feng, J.; Ge, Z.-H., Effects of sintering temperature on thermoelectric properties of Cu1.8S bulk materials. Mater. Res. Express 2020, 7 (1), 015923. DOI 10.1088/2053-1591/ab6c14

44. Zhang, R.; Wu, Y.; Pei, J.; Ge, Z.-H.; Zhang, B.-P.; Sun, Q.; Nie, G., Morphology and phase evolution from CuS to $\mathrm{Cu} 1.8 \mathrm{~S}$ in a hydrothermal process and thermoelectric properties of Cu1.8S bulk. CrystEngComm 2019, 21 (38), 5797-5803. DOI 10.1039/C9CE00936A

45. Li, X.; Hu, C.; Kang, X.; Len, Q.; Xi, Y.; Zhang, K.; Liu, H., Introducing kalium into copper sulfide for the enhancement of thermoelectric properties. J. Mater. Chem. A 2013, 1 (44), 1372113726. DOI 10.1039/C3TA12706K

46. Lim, W. P.; Wong, C. T.; Ang, S. L.; Low, H. Y.; Chin, W. S., Phase-Selective Synthesis of Copper Sulfide Nanocrystals. Chem. Mater. 2006, 18 (26), 6170-6177. DOI 10.1021/cm061686i

47. Mulla, R.; Rabinal, M. K., A tweezer as a thermoelectric tester. Phys. Educ. 2019, 54 (5), 055032. DOI 10.1088/1361-6552/ab3149

48. Rowe, D. M., Thermoelectrics Handbook: Macro to Nano. CRC/Taylor \& Francis: 2006.

49. Mulla, R.; Rabinal, M. K., A Simple and Portable Setup for Thermopower Measurements. ACS Comb. Sci. 2016, 18 (4), 177-181. DOI 10.1021/acscombsci.5b00128

50. Singh, Y., ELECTRICAL RESISTIVITY MEASUREMENTS: A REVIEW. Int. J. Mod. Phys. Conf. Ser. 2013, 22, 745-756. DOI 10.1142/S2010194513010970

51. Fan, P.; Zheng, Z.-h.; Li, Y.-z.; Lin, Q.-y.; Luo, J.-t.; Liang, G.-x.; Cai, X.-m.; Zhang, D.-p.; Ye, F., Low-cost flexible thin film thermoelectric generator on zinc based thermoelectric materials. Appl. Phys. Lett. 2015, 106 (7), 073901. DOI 10.1063/1.4909531

52. Fu, W.; Liu, L.; Yang, G.; Deng, L.; Zou, B.; Ruan, W.; Zhong, H., Oleylamine-Assisted PhaseSelective Synthesis of CU2-xS Nanocrystals and the Mechanism of Phase Control. Part. Part. Syst. Char. 2015, 32 (9), 907-914. DOI 10.1002/ppsc.201500083

53. Zhu, D.; Tang, A.; Peng, L.; Liu, Z.; Yang, C.; Teng, F., Tuning the plasmonic resonance of Cu2-xS nanocrystals: effects of the crystal phase, morphology and surface ligands. J. Mater. Chem. C 2016, 4 (22), 4880-4888. DOI 10.1039/C6TC00980H

54. Freymeyer, N. J.; Cunningham, P. D.; Jones, E. C.; Golden, B. J.; Wiltrout, A. M.; Plass, K. E., Influence of Solvent Reducing Ability on Copper Sulfide Crystal Phase. Cryst. Growth Des. 2013, 13 (9), 4059-4065. DOI 10.1021/cg400895d

55. Kalasad, M. N.; Rabinal, M. K.; Mulimani, B. G., Facile synthesis of bioconjugated fluorescent CdS nanoparticles of tunable light emission. J. Phys. D: Appl. Phys. 2010, 43 (30), 305301. DOI 10.1088/0022-3727/43/30/305301

56. Nakai, I.; Sugitani, Y.; Nagashima, K.; Niwa, Y., X-ray photoelectron spectroscopic study of copper minerals. J. Inorg. Nuclear Chem. 1978, 40 (5), 789-791. DOI 10.1016/0022-1902(78)80152-3

57. Xie, Y.; Riedinger, A.; Prato, M.; Casu, A.; Genovese, A.; Guardia, P.; Sottini, S.; Sangregorio, C.; Miszta, K.; Ghosh, S.; Pellegrino, T.; Manna, L., Copper Sulfide Nanocrystals with Tunable Composition by Reduction of Covellite Nanocrystals with Cu+ Ions. J. Am. Chem. Soc. 2013, 135 (46), 17630-17637. DOI 10.1021/ja409754v

58. Kumar, P.; Nagarajan, R.; Sarangi, R., Quantitative X-ray absorption and emission spectroscopies: electronic structure elucidation of Cu2S and CuS. J. Mater. Chem. C 2013, 1 (13), 2448-2454. DOI 10.1039/C3TC00639E

59. Pattrick, R. A. D.; Mosselmans, J. F. W.; Charnock, J. M.; England, K. E. R.; Helz, G. R.; Garner, C. D.; Vaughan, D. J., The structure of amorphous copper sulfide precipitates: An X-ray absorption study. Cosmochim. Acta 1997, 61 (10), 2023-2036. DOI 10.1016/S0016-7037(97)00061-6

60. Nozaki, H.; Shibata, K.; Ohhashi, N., Metallic hole conduction in CuS. J. Solid State Chem. 1991, 91 (2), 306-311. DOI 10.1016/0022-4596(91)90085-V 
61. Plackowski, C.; Hampton, M. A.; Bruckard, W. J.; Nguyen, A. V., An XPS investigation of surface species formed by electrochemically induced surface oxidation of enargite in the oxidative potential range. Miner. Eng. 2014, 55, 60-74. DOI 10.1016/j.mineng.2013.08.010

62. Yang, Y.; Harmer, S.; Chen, M., Synchrotron-based XPS and NEXAFS study of surface chemical species during electrochemical oxidation of chalcopyrite. Hydrometallurgy 2015, 156, 8998. DOI 10.1016/j.hydromet.2015.05.011

63. Mansour, B. A.; El Soud, A. M. A.; Tahoon, K. H., Evaluation of Some Physical Quantities in the Two-Phase Region in Copper Sulphides. phys. status solidi a 1992, 132 (1), 59-65. DOI 10.1002/pssa.2211320107

64. Tarachand; Hussain, S.; Lalla, N. P.; Kuo, Y. K.; Lakhani, A.; Sathe, V. G.; Deshpande, U.; Okram, G. S., Thermoelectric properties of Ag-doped CuS nanocomposites synthesized by a facile polyol method. Phys. Chem. Chem. Phys. 2018, 20 (8), 5926-5935. DOI 10.1039/C7CP07986A

65. Mulla, R.; Rabinal, M. K., Large-scale synthesis of copper sulfide by using elemental sources via simple chemical route. Ultrason. Sonochem. 2017, 39, 528-533. DOI 10.1016/j.ultsonch.2017.05.027

66. Jiang, Q.; Yan, H.; Khaliq, J.; Shen, Y.; Simpson, K.; Reece, M. J., Enhancement of thermoelectric properties by atomic-scale percolation in digenite CuxS. J. Mater. Chem. A 2014, 2 (25), 9486-9489. DOI 10.1039/C4TA01250J

67. He, Y.; Day, T.; Zhang, T.; Liu, H.; Shi, X.; Chen, L.; Snyder, G. J., High Thermoelectric Performance in Non-Toxic Earth-Abundant Copper Sulfide. Adv. Mater. 2014, 26 (23), 3974-3978. DOI 10.1002/adma.201400515

68. Chen, X.; Zhang, H.; Zhao, Y.; Liu, W.-D.; Dai, W.; Wu, T.; Lu, X.; Wu, C.; Luo, W.; Fan, Y.; Wang, L.; Jiang, W.; Chen, Z.-G.; Yang, J., Carbon-Encapsulated Copper Sulfide Leading to Enhanced Thermoelectric Properties. ACS Appl. Mater. Interfaces 2019, 11 (25), 22457-22463. DOI 10.1021/acsami.9b06212

69. Suwardi, A.; Bash, D.; Ng, H. K.; Gomez, J. R.; Repaka, D. V. M.; Kumar, P.; Hippalgaonkar, K., Inertial effective mass as an effective descriptor for thermoelectrics via data-driven evaluation. J. Mater. Chem. A 2019, 7 (41), 23762-23769. DOI 10.1039/C9TA05967A

70. Guan, M.-J.; Qiu, P.-F.; Song, Q.-F.; Yang, J.; Ren, D.-D.; Shi, X.; Chen, L.-D., Improved electrical transport properties and optimized thermoelectric figure of merit in lithium-doped copper sulfides. Rare Metals 2018, 37 (4), 282-289. DOI 10.1007/s12598-018-1007-0

71. Wang, L.; Liu, Y.; Zhang, Z.; Wang, B.; Qiu, J.; Hui, D.; Wang, S., Polymer composites-based thermoelectric materials and devices. Compos. B. Eng. 2017, 122, 145-155. DOI 10.1016/j.compositesb.2017.04.019

72. Shah, K. W.; Wang, S.-X.; Zheng, Y.; Xu, J., Solution-Based Synthesis and Processing of Metal Chalcogenides for Thermoelectric Applications. Appl. Sci. 2019, 9 (7), 1511. DOI 10.3390/app9071511

73. Zhang, Y.; Park, S.-J., Flexible Organic Thermoelectric Materials and Devices for Wearable Green Energy Harvesting. Polymers 2019, 11 (5). DOI 10.3390/polym11050909

74. Liu, Z.; Chen, G., Advancing Flexible Thermoelectric Devices with Polymer Composites. Adv. Mater. Technol. 2020, 5(7), 2000049. DOI 10.1002/admt.202000049

75. Oh, J. Y.; Lee, J. H.; Han, S. W.; Chae, S. S.; Bae, E. J.; Kang, Y. H.; Choi, W. J.; Cho, S. Y.; Lee, J.-O.; Baik, H. K.; Lee, T. I., Chemically exfoliated transition metal dichalcogenide nanosheetbased wearable thermoelectric generators. Energy Environ. Sci. 2016, 9 (5), 1696-1705. DOI 10.1039/C5EE03813H

76. Sun, T.; Zhou, B.; Zheng, Q.; Wang, L.; Jiang, W.; Snyder, G. J., Stretchable fabric generates electric power from woven thermoelectric fibers. Nat. Commun. 2020, 11 (1), 572. DOI 10.1038/s41467-020-14399-6

77. Du, Y.; Xu, J.; Paul, B.; Eklund, P., Flexible thermoelectric materials and devices. Appl. Mater. Today 2018, 12, 366-388. DOI 10.1016/j.apmt.2018.07.004 
78. Mulla, R.; Jones, D. R.; Dunnill, C. W., Thermoelectric Paper: Graphite Pencil Traces on Paper to Fabricate a Thermoelectric Generator. Adv. Mater. Technol. 2020, 5 (7), 2000227. DOI 10.1002/admt.202000227

79. Roy, P.; Srivastava, S. K., Nanostructured copper sulfides: synthesis, properties and applications. CrystEngComm 2015, 17 (41), 7801-7815. DOI 10.1039/C5CE01304F 